\title{
Indications for revascularization in patients with left ventricular dysfunction: Evidence and uncertainties
}

\author{
Robert O. Bonow, MD, MS
}

Surgical treatment of coronary artery disease (CAD) ranks among the greatest advances in medicine in the 20th century and remains the leading form of cardiovascular surgery in the world's developed countries, despite improvements in medical therapy and the growth of percutaneous coronary intervention (PCI). In 2010, nearly 400,000 coronary artery bypass graft (CABG) procedures were performed in the United States. ${ }^{1}$ In-hospital mortality rates related to the procedure have declined substantially for both men and women, despite increases in overall age and comorbidities. $^{2}$

Among symptomatic patients, revascularization with either PCI or CABG results in better symptom relief and improved quality of life compared with medical management. ${ }^{3,4}$ CABG provides superior long-term survival rates compared with PCI in patients with the most-complex multivessel disease and those with diabetes. ${ }^{5-8}$ Thus, for the most part, the role of the CABG in the management of CAD is well established, with strong evidence-based guidelines and recommendations to improve outcomes in patients with left main disease, 3-vessel disease, and severe stenosis of the proximal left anterior descending artery. ${ }^{9-12}$ However, the impact of having CABG on survival in patients with left ventricular (LV) dysfunction, particularly severe LV dysfunction, remains a subject of considerable debate and uncertainty.

Numerous early studies of CABG versus medical therapy in patients with $\mathrm{LV}$ dysfunction uniformly suggested that CABG results in improved survival, with enhanced survival rates compared with medical management, ranging from $10 \%$ to $50 \%{ }^{13-17}$ However, these nonrandomized studies were predominately retrospective and predate the use of modern evidence-based medical therapies for LV dysfunction; many predate the use of internal mammary grafts.

In addition, the seminal randomized trials of CABG versus medical therapy fail to provide definitive insights in the case of such patients, partly because these trials were

\footnotetext{
From the Center for Cardiovascular Innovation, Department of Medicine, Northwestern University Feinberg School of Medicine, Chicago, Ill. Disclosures: Author has nothing to disclose with regard to commercial support. Address for reprints: Robert O. Bonow, MD, MS, Center for Cardiovascular Innovation, Northwestern University Feinberg School of Medicine, 201 East Huron St, Galter 3-150, Chicago, IL 60611 (E-mail: r-bonow@northwestern.edu). J Thorac Cardiovasc Surg 2014;148:2461-5 $0022-5223 / \$ 36.00$

Copyright (c) 2014 by The American Association for Thoracic Surgery http://dx.doi.org/10.1016/j.jtcvs.2014.10.100
}

performed in an era before current medical management for LV dysfunction with beta-adrenergic blockers, angiotensin converting-enzyme inhibitors, and statins. In addition, patients with a severely reduced LV ejection fraction (EF) were excluded from randomization. Although $26 \%$ of patients in the Veterans Administration Cooperative Study ${ }^{18}$ had EF values $<45 \%$, none was considered to have severe LV dysfunction. The European Surgery Study ${ }^{19}$ excluded patients with an EF $<50 \%$. The Coronary Artery Surgery Study excluded patients with an EF $<35 \%$ and those in New York Heart Association functional class III-IV. ${ }^{20}$ The Coronary Artery Surgery Study enrolled only 160 patients with mild-moderate LV dysfunction (EF, $35 \%-49 \%$ ); the finding of improved survival with surgical therapy compared with medical therapy in patients who had 3-vessel disease and this degree of LV dysfunction was based on a total of only 78 patients. ${ }^{21}$ The Coronary Artery Bypass Graft Surgery Trialists Collaboration meta-analysis of 7 clinical trials of CABG surgery versus medical therapy ${ }^{3}$ included only 178 patients $(7 \%$ of the total) with an $\mathrm{EF}<40 \%$.

More recent randomized trials investigating outcomes in patients receiving intensive contemporary medical therapy for CAD versus myocardial revascularization ${ }^{4,22,23}$ have largely excluded patients with severe LV dysfunction. In addition, prospective randomized trials of CABG versus PCI have enrolled predominately patients with normal LV function, and none focused specifically on patients with a depressed $\mathrm{EF}^{5,6,24}$

\section{THE SURGICAL TREATMENT FOR ISCHEMIC HEART FAILURE TRIAL}

The Surgical Treatment for Ischemic Heart Failure (STICH) trial ${ }^{25}$ emerges as the first and only prospective randomized trial designed to determine the impact of CABG when it is added to evidence-based medical therapy in patients with CAD and an EF $\leq 35 \%$. The STICH trial investigated 2 hypotheses: that survival is enhanced with CABG plus evidence-based medical therapy compared with medical therapy alone in patients with ischemic heart failure (the revascularization hypothesis); and that CABG plus surgical ventricular reconstruction (SVR) provides a survival advantage compared with $\mathrm{CABG}$ alone, in patients with an $\mathrm{EF} \leq 35 \%$ undergoing revascularization who have dominant LV anterior akinesia or dyskinesia (the SVR hypothesis). Patients with left main stenosis or significant angina pectoris (Canadian Heart Association functional class III-IV) were eligible to participate in the SVR 
hypothesis of the trial but not the revascularization hypothesis.

\section{Revascularization Versus Medical Therapy}

The STICH trial revascularization hypothesis enrolled 1212 patients in 99 international sites, with 602 randomized to receive medical therapy and 610 to receive $\mathrm{CABG}$ plus medical therapy. ${ }^{26}$ In patients undergoing surgery, the goal was to achieve complete revascularization and implement internal mammary grafts whenever possible; internal mammary grafts were employed in $91 \%$ of patients. Evidence-based medical therapy in both the surgical and medical arms of the study achieved high levels of adherence, including beta-blocking agents (in $91 \%$ of patients at 1 year); angiotensin converting-enzyme inhibitors or angiotensin-receptor antagonists (91\%); statins (91\%); and aspirin (88\%), with $93 \%$ receiving either aspirin or warfarin.

The primary outcome was all-cause mortality. The principal result ${ }^{26}$ was the lack of significant difference in all-cause mortality between the 2 groups during the 56-month mean follow-up period, with $41 \%$ and $36 \%$ mortality in those assigned to medical therapy and CABG, respectively $(P=.12)$. Thus, using the prespecified intention-to-treat analysis, the study must be interpreted as a negative trial.

However, several considerations suggest a more favorable outcome in those receiving CABG. First, secondary endpoints included cardiovascular mortality and the combination of all-cause mortality plus cardiovascular hospitalization, and both of these endpoints were significantly reduced by CABG compared with medical therapy $(P=.05$ and $P<.001$, respectively). Second, a small but important number of crossovers occurred, with 55 patients randomized to the CABG arm who never received $\mathrm{CABG}$, and 65 patients randomized to medical therapy who underwent an early $\mathrm{CABG}$ procedure. Analysis of outcomes based on patients who actually received $\mathrm{CABG}$ versus medical therapy reveals highly significant reductions in mortality with CABG, using either an analysis of actual treatment received or a per-protocol analysis that excludes the crossovers $(P<.001$ and $P=.005$, respectively). ${ }^{26,27}$ Finally, symptom status and quality of life were substantially better in patients randomized to receive $\mathrm{CABG}$ throughout the duration of follow-up. ${ }^{28}$

Thus, depending on the perspective taken - that of a clinical trialist (intention-to-treat), or that of patients, clinicians, and surgeons (actual treatment received) - the STICH study can be interpreted as either a negative or positive trial, with respect to the impact of CABG on survival of patients with ischemic LV dysfunction. In both the primary intention-to-treat analysis and the subsequent analyses adjusting for crossovers, patients undergoing
CABG did face an early higher risk related to perioperative mortality, and this higher up-front risk of surgery needs to be an inherent part of the discussions with patients, balanced against the longer-term benefits of revascularization.

\section{Subgroup Analyses of CABG Versus Medical Therapy}

Several ancillary analyses of the STICH trial have been reported that explore potential subgroups of patients with LV dysfunction who may be most likely to benefit from CABG. The presence and extent of myocardial viability was addressed in a prospectively designed STICH substudy, ${ }^{29}$ with 601 of the 1212 patients imaged with single-photon emission tomography or low-dose dobutamine echocardiography to determine the magnitude of viable myocardium. Using prespecified definitions of extent of myocardial viability, patients with predominately viable myocardium had reduced mortality compared with those with predominately nonviable myocardium: $37 \%$ versus $51 \%$, respectively, over a median 5.1 -year follow-up period. However, no significant interactions were found among presence or absence of viable myocardium, assignment to CABG or medical therapy, and survival. Additional prespecified secondary analyses that were based on median viability scores or on a continuous model of viability and risk similarly revealed no significant interactions.

These findings run counter to the prevailing opinions that myocardial viability testing would identify those patients most likely to benefit from CABG, based on numerous previous imaging studies assessing survival with CABG compared with medical therapy, and most notably, a meta-analysis of viability studies by Allman and colleagues. ${ }^{30}$ The major weakness of these previous studies, in addition to their retrospective design and heterogeneous definitions of myocardial viability, is that the medical management would be considered inadequate by today's standards. For example, the many reports summarized by Allman and colleagues ${ }^{30}$ were performed in the 1980s and 1990s, and very few (if any) patients received beta-blockers, reflected in the $16 \%$ annual mortality rate reported in patients with viable myocardium treated medically. In contrast, the annual mortality rate with medical therapy in patients with viable myocardium in the STICH trial was only $7.1 \%$, despite the greater degree of LV dysfunction (mean EF of $26.7 \%$ in the STICH trial compared with $32.9 \%$ in the meta-analysis). Although the STICH trial viability data cannot be considered conclusive, they are supported by data in a smaller randomized trial of CABG versus medical therapy in patients with ischemic LV dysfunction and evidence of myocardial viability, in which $\mathrm{CABG}$ did not result in improved survival. ${ }^{31}$ 
The updated 2014 European guidelines for myocardial revascularization ${ }^{12}$ continue to recommend that CABG surgery in patients with LV dysfunction be considered in the presence of viable myocardium, but cite only the meta-analysis by Allman and colleagues ${ }^{30}$ in support of this recommendation. As noted, none of the studies summarized in that meta-analysis provided current, aggressive, evidence-based therapies (particularly betablockers) in the patients receiving "medical management." The European guidelines for management of heart failure ${ }^{32}$ do not recommend CABG (class III) surgery in patients with LV dysfunction without angina and without myocardial viability. In contrast, the 2013 U.S. guidelines for management of heart failure ${ }^{33}$ indicate that it is reasonable to consider $\mathrm{CABG}$ in patients with moderate $\mathrm{LV}$ dysfunction (EF, 35\%-50\%) and multivessel CAD or disease of the proximal left anterior descending artery when viable myocardium is present. However, in patients with severe LV dysfunction (EF, $<35 \%$ ), CABG may be considered with the intent of improving survival, whether or not viable myocardium is present. These latter recommendations are in keeping with the results of the STICH trial.

Additional analyses of the STICH trial demonstrated that the differences in the effect of CABG on survival is not influenced by the presence and extent of inducible myocardial ischemia ${ }^{34}$ or by circulating levels of biomarkers ${ }^{35}$ such as brain natriuretic peptide and soluble tumor necrosis factor- $\alpha$ receptor-1. Rather, improved survival with CABG seems to be predicated on preserved functional status, as assessed by the Kansas City Cardiomyopathy Questionnaire or the 6-minute walk test $^{36}$ and markers of angiographic severity of CAD, severity of LV systolic dysfunction, and extent of LV remodeling. ${ }^{37}$ Thus, survival after CABG is related to functional status of the patient, severity of CAD, and severity of LV remodeling, and less to objective markers of viability or ischemia. Patients most likely to benefit are those with the most-severe CAD and most-advanced LV dysfunction. These are also the patients at greatest risk.

\section{Surgical Ventricular Reconstruction}

Whether it is advisable to add SVR to a CABG procedure, with the intent to restore LV size and shape, and in so doing enhancing LV reverse remodeling beyond what can be achieved with revascularization and aggressive medical management, has been the subject of considerable discussion and controversy. Although this procedure had strong proponents and encouraging clinical results, ${ }^{38,39}$ previous studies were observational and unblinded in nature, and SVR had never been subjected to a prospective clinical trial comparing the results with those of CABG alone, particularly against the background of intensive evidence-based medical therapy. The SVR hypothesis of the STICH trial $^{40}$ addresses this gap, enrolling 1000 patients with $\mathrm{LV}$ dysfunction, CAD amenable to CABG, and anterior wall akinesia or dyskinesia amenable to SVR. Of these, 499 were randomized to receive CABG alone, and 501 to receive CABG plus SVR.

As anticipated, SVR resulted in significantly smaller LV volumes, but no difference was found in the primary combined endpoint of all-cause mortality and cardiac hospitalization, during the median follow-up of 4 years, between patients receiving CABG or CABG plus SVR, which occurred in $59 \%$ and $58 \%$ of patients, respectively. In addition, no differences were found in the rate of individual secondary endpoints including all-cause mortality, hospitalization, myocardial infarction, and stroke. Quality measures also did not differ between the 2 groups, although SVR resulted in greater utilization of health care resources. ${ }^{41}$ Patients more likely to benefit from SVR procedures are those with smaller, less-remodeled left ventricles, ${ }^{42}$ whereas the extent of myocardial viability in the anterior wall does not seem to be an important determinant of outcomes of SVR compared with CABG alone. ${ }^{43}$

\section{CONCLUSIONS}

With the increasing global burden of heart failure, it is important to recognize that CAD is the leading cause of LV systolic dysfunction in developed countries of the world, and in many developing countries as well. CAD as the causative etiology results in a more aggressive natural history, with higher mortality rates than nonischemic etiologies, ${ }^{44}$ particularly in patients with the most-severe degrees of LV dysfunction ${ }^{45}$ (EF $<35 \%$ ). Although evidence-based medical therapy remains the foundation for treatment of all patients with LV systolic dysfunction, CABG provides the potential for incremental survival benefit, particularly among the highest-risk patients with multivessel disease and the most severely remodeled ventricles. The results of the prospective STICH trial $^{26}$ support those of many earlier nonrandomized studies, ${ }^{13-17}$ showing that the longer-term survival benefit in patients who undergo CABG compared with medical therapy alone tends to offset the short-term perioperative mortality risk. Decisions to proceed with $\mathrm{CABG}$ in the highest-risk patients need to be made judiciously and are best deliberated with coordinated input from a dedicated multidisciplinary heart team.

\section{References}

1. Go AS, Mozaffarian D, Roger VL, Benjamin EJ, Berry JD, Blaha MJ, et al. Heart disease and stroke statistics-2014 update: a report from the American Heart Association. Circulation. 2014;129:e28-292.

2. Holmes JS, Kozak LJ, Owings MF. Use and in-hospital mortality associated with two cardiac procedures, by sex and age: national trends, 1990-2004. Health Aff (Millwood). 2007;26:169-77.

3. Yusuf S, Zucker D, Passamani E, Peduzzi P, Takaro T, Fisher LD, et al. Effect of coronary artery bypass graft surgery on survival: overview of 10-year results 
from randomised trials by the Coronary Artery Bypass Graft Surgery Trialists Collaboration. Lancet. 1994;344:563-70.

4. Boden WE, O'Rourke RA, Teo KK, Hartigan PM, Maron DJ, Kostuk WJ, et al Optimal medical therapy with or without PCI for stable coronary disease. $N$ Engl J Med. 2007;356:1503-16.

5. Bypass Angioplasty Revascularization Investigation (BARI) investigators Comparison of coronary bypass surgery with angioplasty in patients with multivessel disease. N Engl J Med. 1996;335:217-25.

6. Serruys PW, Morice MC, Kappetein AP, Colombo A, Holmes DR, Mack MJ, et al. Percutaneous coronary intervention versus coronary-artery bypass grafting for severe coronary artery disease. N Engl J Med. 2009;360:961-72.

7. Weintraub WS, Grau-Sepulveda MV, Weiss JM, O'Brien SM, Peterson ED, Kolm P, et al. Comparative effectiveness of revascularization strategies. $N$ Engl J Med. 2012;366:1467-76

8. Farkouh ME, Domanski M, Sleeper LA, Siami FS, Dangas G, Mack M, et al Strategies for multivessel revascularization in patients with diabetes. $N$ Engl J Med. 2012:367:2375-84.

9. Hillis LD, Smith PK, Anderson JL, Bittl JA, Bridges CR, Byrne JG, et al. 2011 ACCF/AHA guideline for coronary artery bypass graft surgery. A report of the American College of Cardiology Foundation/American Heart Association Task Force on Practice Guidelines. J Am Coll Cardiol. 2011:58:e123-210.

10. Fihn SD, Gardin JM, Abrams J, Berra K, Blankenship JC, Dallas AP, et al. 2012 ACCF/AHA/ACP/AATS/PCNA/SCAI/STS guideline for the diagnosis and management of patients with stable ischemic heart disease. A report of the American College of Cardiology Foundation/American Heart Association Task Force on Practice Guidelines, American Association for Thoracic Surgery, Preventive Cardiovascular Nurses Association, Society for Cardiovascular Angiography and Interventions, and Society of Thoracic Surgeons. J Am Coll Cardiol. 2012;60:e44-164.

11. Patel MR, Dehmer GD, Hirshfeld JW, Smith PK, Spertus JA. ACCF/SCAI/STS/ AATS/AHA/ASNC/HFSA/SCCT 2012 appropriate use criteria for coronary revascularization focused update. A report of the American College of Cardiology Foundation Appropriate Use Criteria Task Force, Society for Cardiovascular Angiography and Interventions, Society of Thoracic Surgeons, American Association for Thoracic Surgery, American Heart Association, American Society of Nuclear Cardiology, and the Society of Cardiovascular Computed Tomography. J Am Coll Cardiol. 2012;59:857-81.

12. Windecker S, Kolh P, Alfonso F, Collet JP, Cremer J, Falk V, et al. 2014 ESC EACTS guidelines on myocardial revascularization. The Task Force on Myocardial Revascularization of the European Society of Cardiology (ESC) and the European Association for Cardio-Thoracic Surgery (EACTS). Developed with the special contribution of the European Association of Percutaneous Cardiovascular Interventions (EAPCI). Eur Heart J. 2014;35:2541-619.

13. Manley JC, King JF, Left HJ, Johnson WD. The "bad" left ventricle: results of coronary surgery and effect on late survival. J Thorac Cardiovasc Surg. 1976;72: 841-8.

14. Vlietstra RE, Assad-Morell JL, Frye RL, Elveback LR, Connolly DC, Ritman EL, et al. Survival predictors in coronary artery disease: medical and surgical comparisons. Mayo Clin Proc. 1977:52:85-90.

15. Faulkner SL, Stoney WS, Alford WC. Ischemic cardiomyopathy: medical versus surgical treatment. J Thorac Cardiovasc Surg. 1977;74:77-82.

16. Alderman EL, Fischer P, Litwin GC, Kaiser GC, Myers WO, Maynard C, et al. Results of coronary artery surgery in patients with poor left ventricular function (CASS). Circulation. 1983;68:785-95

17. O'Connor CM, Velazquez EJ, Gardner LH, Smith PK, Newman MF Landolfo KP, et al. Comparison of coronary artery bypass grafting versus medical therapy on long-term outcome in patients with ischemic cardiomyopathy (a 25year experience from the Duke Cardiovascular Disease Databank). Am J Cardiol. 2002;90:101-7

18. Veterans Administration Coronary Artery Bypass Surgery Cooperative Study group. Eleven-year survival in the Veterans Administration randomized trial of coronary bypass surgery for stable angina. $N$ Engl J Med. 1984;311: 1333-9.

19. Varnauskas E. European Coronary Surgery Study group. Twelve-year follow-up of survival in the randomized European Coronary Surgery Study. N Engl J Med. 1988;319:332-7.

20. Coronary Artery Surgery Study (CASS): a randomized trial of coronary artery bypass surgery: survival data. Circulation. 1983;68:939-50.

21. Passamani E, Davis KB, Gillespie MJ, Killip T. Coronary Artery Surgery Study group. A randomized trial of coronary artery bypass surgery: survival of patients with a low ejection fraction. N Engl J Med. 1985;312:1665-71.
22. Hueb W, Soares PR, Gersh BJ, César LA, Luz PL, Puig LB, et al. The Medicine, Angioplasty, or Surgery Study (MASS-II): a randomized, controlled clinical trial of three therapeutic strategies for multivessel coronary artery disease: one-year results. J Am Coll Cardiol. 2004;43:1743-51.

23. BARI 2D Study Group. A randomized trial of therapies for type 2 diabetes and coronary artery disease. N Engl J Med. 2009:360:2503-15.

24. Bravata DM, McDonald KM, Gienger AL, Sundaram V, Perez MV, Varghese R, et al. Comparative effectiveness of percutaneous coronary interventions and coronary artery bypass grafting for coronary artery disease. Rockville, MD: Agency for Healthcare Research and Quality; 2007.

25. Velazquez EJ, Lee KL, O'Connor CM, Oh JK, Bonow RO, Pohost GM, et al. The rationale and design of the Surgical Treatment for Ischemic Heart Failure (STICH) trial. J Thorac Cardiovasc Surg. 2007;134:1540-7.

26. Velazquez EJ, Lee KL, Deja MA, Jain A, Sopko G, Marchenko A, et al. Coronary-artery bypass surgery in patients with left ventricular dysfunction. N Engl J Med. 2011;364:1607-16.

27. Doenst T, Cleland JGF, Rouleau JL, She L, Wos S, Ohman EM, et al. Influence of crossover on mortality in a randomized study of revascularization in patients with systolic heart failure and coronary artery disease. Circ Heart Fail. 2013;6: 443-50.

28. Mark DB, Knight JD, Velazquez EJ, Wasilewski J, Howlett JG, Smith PK, et al. Quality of life outcomes with coronary artery bypass graft surgery in ischemic left ventricular dysfunction: results from the STICH Trial. Ann Intern Med. 2014;161:392-9.

29. Bonow RO, Maurer G, Lee KL, Holly TA, Binkley PF, Desvigne-Nickens P, et al. Myocardial viability and survival in ischemic left ventricular dysfunction. $N$ Engl J Med. 2011;364:1617-25.

30. Allman KC, Shaw LJ, Hachamovitch R, Udelson JE. Myocardial viability testing and impact of revascularization on prognosis in patients with coronary artery disease and left ventricular dysfunction: a meta-analysis. J Am Coll Cardiol. 2002;39:1151-8.

31. Cleland JGF, Calvert M, Freemantle N, Arrow Y, Ball SG, Bonser RS, et al The Heart Failure Revascularisation Trial (HEART). Eur J Heart Fail. 2011;13 227-33.

32. McMurray JJV, Adamopoulos S, Anker SD, Auricchio A, Böhm M, Dickstein K, et al. ESC guidelines for the diagnosis and treatment of acute and chronic heart failure 2012. The Task Force for the Diagnosis and Treatment of Acute and Chronic Heart Failure 2012 of the European Society of Cardiology. Developed in collaboration with the Heart Failure Association (HFA) of the ESC. Eur Heart J. 2012;33:1787-847.

33. Yancy CW, Jessup M, Bozkurt B, Butler J, Casey DE, Drazner MH, et al. 2013 ACCF/AHA guideline for the management of heart failure. A report of the American College of Cardiology Foundation/American Heart Association Task Force on Practice Guidelines. J Am Coll Cardiol. 2013;62:e147-239.

34. Panza JA, Holly TA, Asch FM, She L, Pellikka PA, Velazquez EJ, et al. Inducible myocardial ischemia and outcomes in patients with coronary artery disease and left ventricular dysfunction. J Am Coll Cardiol. 2013;61:1860-70.

35. Feldman AM, Mann DL, She L, Bristow MR, Maisel AS, McNamara DM, et al Prognostic significance of biomarkers in predicting outcome in patients with coronary artery disease and left ventricular dysfunction: results of the biomarker substudy of the Surgical Treatment for Ischemic Heart Failure Trials. Circ Heart Fail. 2013;6:461-72.

36. Stewart RAH, Szalewska D, She L, Lee KL, Drazner MH, Lubiszewska B, et al. Exercise capacity and mortality in patients with ischemic left ventricular dysfunction randomized to coronary artery bypass graft surgery or medical therapy: an analysis from the STICH Trial. JACC Heart Fail. 2014;2:335-43.

37. Panza JA, Velazquez EJ, She L, Smith PK, Nicolau JC, Favaloro RR, et al. Extent of coronary and myocardial disease and benefit from surgical revascularization in LV dysfunction. J Am Coll Cardiol. 2014;64:553-61.

38. Athanasuleas CL, Buckberg GD, Stanley AWH, Siler W, Dor V, Di Donato M, et al. Surgical ventricular restoration in the treatment of congestive heart failure due to post-infarction ventricular dilation. J Am Coll Cardiol. 2004:44:1439-45.

39. Menicanti L, Castelvecchio S, Ranucci M, Frigiola A, Santambrogio C, de Vincentiis C, et al. Surgical therapy for ischemic heart failure: single-center experience with surgical anterior ventricular restoration. J Thorac Cardiovasc Surg. 2007; 134:433-41.

40. Jones RH, Velazquez EJ, Michler RE, Sopko G, Oh JK, O'Connor CM, et al Coronary bypass surgery with or without surgical ventricular reconstruction N Engl J Med. 2009;360:1705-17.

41. Mark DB, Knight JD, Velazquez EJ, Howlett JG, Spertus JA, Djokovic LT, et al Quality of life and economic outcomes with surgical ventricular reconstruction in 
ischemic heart failure: results from the Surgical Treatment for Ischemic Heart Failure trial. Am Heart J. 2009;157:837-44.e3.

42. Michler RE, Rouleau JL, Al-Khalidi H, Bonow RO, Pellikka PA, Pohost GM, et al. Insights from the STICH trial: change in left ventricular size after coronary artery bypass graft surgery with and without surgical ventricular reconstruction. J Thorac Cardiovasc Surg. 2013;146:1139-45.

43. Holly TA, Bonow RO, Arnold JMO, Oh JK, Varadarajan P, Pohost GM, et al. Relation between the presence of myocardial scar and the benefit of adding surgical ventricular reconstruction to coronary bypass surgery in patients with coronary artery disease and severe left ventricular dysfunction: results of the Surgical Treatment for Ischemic Heart Failure (STICH) Trial. J Thorac Cardiovasc Surg. 2014;148:2677-84.

44. Felker GM, Shaw LK, O'Connor CM. A standardized definition of ischemic cardiomyopathy for use in clinical research. J Am Coll Cardiol. 2002;39: 210-8.

45. Emond M, Mock MB, Davis KB, Fisher LD, Holmes DR Jr, Chaitman BR, et al. Long-term survival of medically treated patients in the Coronary Artery Surgery Study (CASS) Registry. Circulation. 1994;90:2654-7. 